\title{
Research about Architecture and Key Technology of User Side Internet of Energy
}

\author{
Songsong Chen ${ }^{1, \text { a }}$, Wei Wang ${ }^{2, b}$, Dezhi Li ${ }^{1, \mathrm{c}}$ and Ming Zhong ${ }^{1, \mathrm{~d}}$ \\ ${ }^{1}$ China Electric Power Research Institute, China \\ ${ }^{2}$ State Grid Corporation of China, China \\ achensongsong@epri.sgcc.com.cn, ${ }^{b} 369648010 @ q q . c o m,{ }^{C}$ lidezhi@epri.sgcc.com.cn, \\ zhongm@epri.sgcc.com.cn
}

\begin{abstract}
Keywords: User side energy internet, Energy router, Energy interconnection local area network, Demand side.

Abstract. Energy Internet is a kind of new type information-energy fusion "Wan" which is constructed with Internet concept, based on open structure, trend hierarchical classification. User Side Internet of Energy, namely energy local area network, that is to establish the cooling heating power supply mode mainly on smart grid on the user side, use the renewable energy efficiently, realize the transformation and share of various forms of energy, improve energy comprehensive utilization efficiency, realize the cold thermal power and other energy joint optimized operation and energy echelon use, promote energy production, consumption, technology and system revolution of the demand side. In this paper, around the user energy Internet, the research status at home and abroad was summarized, the definition and characteristics was given, key technology was analyzed. In addition, basic structure of the user side energy Internet was promoted, energy router and energy information interaction mechanism was discussed, which provided new way of thinking for promoting the application of energy Internet in low carbon urban, intelligent park / cell, etc.
\end{abstract}

\section{Introduction}

A Large scale use of fossil energy has resulted in increasingly serious climate change and other environmental crisis. The economic development models that seriously depend on traditional energy are difficult to continue and it is widely agreed to actively look for ways to use the new energy. The rapid development of renewable energy and information communication technology has created favorable conditions for the development of the energy Internet. Jeremy Rifkin, a famous American scholar, put forward the vision of energy Internet in his new book The Third Industrial Revolution. Energy Internet is a new type of energy utilization system, which is based on the new energy technology and combines advanced information technology, and its typical features mainly include: (1) high proportion of renewable energy; (2) allowing to connect a large number of distributed generation and energy storage devices; (3) wide area sharing of energy; (4) traffic electrification. As the combination of the energy field and information field, energy Internet has received extensive attention in the concept of the third industrial revolution and hs been regarded as the core technology in the field of future energy.

The United States, Germany, Japan and so on, have begun a study of the energy Internet. The National Science Foundation of the United States studied the new power grid structure in 2008. Based on the renewable energy power generation and distributed energy storage device, this structure of power network realized cleanness and flexibility of the power grid. The Future Renewable Electric Energy Delivery and Management (FREEDM) system can build energy internet by realizing distributed system control with power electronic technology. Germany also put forward the idea of E-Energy in the same year. In 2011, Japan launched the Mark one energy router to achieve the cooperation of the energy interconnection local area network.

Domestic research started late, so the existing related research is still in the stage of theoretical research. In 2013, State Grid formally put the concept of energy Internet to a strategic height and emphasized it in the smart grid and the third industrial revolution. In 2014, National Energy 
Administration, State Grid held strategic meetings about energy Internet separately,which to a certain extent, laid the foundation for the development of energy Internet.

In the future, information and communication technology will play a more critical role in the field of energy, and the concept of green energy and smart energy will be promoted by the intelligent information network, energy equipment and growing new energy generator units. The original energy management system is upgraded to active participation, multi interactive interactive system by information exchange in heterogeneous energy systems, the new system provides energy services for the implementation of automatic demand response and energy efficiency management and reduce the risk of system instability. This paper proposed the definition and characteristics of user side energy Internet, analysed the key technologies of user side energy Internet, proposed the basic framework of the user side energy Internet, discussed of energy router and the interaction mechanism of energy information.

\section{The definition and characteristics of User Side Internet of Energy}

Energy Internet is a kind of new type energy network which is constructed by the traditional power grid and with the assistant of distributed power, energy storage system and information network[13-15]. By using informationization method, Energy Internet interconnects distributed energy storage and energy-harvesting device, which provides the exchange of energy flow and information flow with basic network [16][17]. Energy Internet is based on the widely use of renewable energy power generation, including various types of power generation, such as conventional energy, large-scale new energy and large capacity storage. However, with the large-scale access of renewable energy, the stability of power grid is being impacted fiercely. Under this current situation, the traditional energy network faces the transformation in the direction of Energy Internet[18-20]. Affected by the energy crisis, our country developed energy conservation and emissions reduction, issued and implemented power demand side management measures, implement double control policy for the total energy consumption, strived to develop renewable energy, encourage distributed power widely access on the user side. So far, China has been basically with policy conditions infrastructure of developing Energy Internet. But the technology architecture design of Energy Internet is related to the development of the whole industry, affects the associated equipment manufacturing and project implementation.

Figure 1 is the conceptual model of Energy Internet in user domain, which refers to the smart grid concept model and is designed for User Side Internet of Energy. At present, the picture shows industry, commercial and residential users of the power flow interaction. And considering the specific device on user side involved cold flow, heat flow and natural gas flow, cooperating with the existing power flow and information flow on user side, we build all elements of Energy Internet. Considering the demand of the security management, Energy Internet builds a large amount of redundancy to ensure the system's reliability, and uses distributed route to realize dynamic reserve of devices and lines. By using power electronics and information technology, a large number of distributed energy, energy storage and load can connect with each other through Energy Internet, realizing bidirectional energy flow and resource sharing, helping the smart energy management system to monitor the grid power quality, and controling intelligent terminals through power management on user side. 


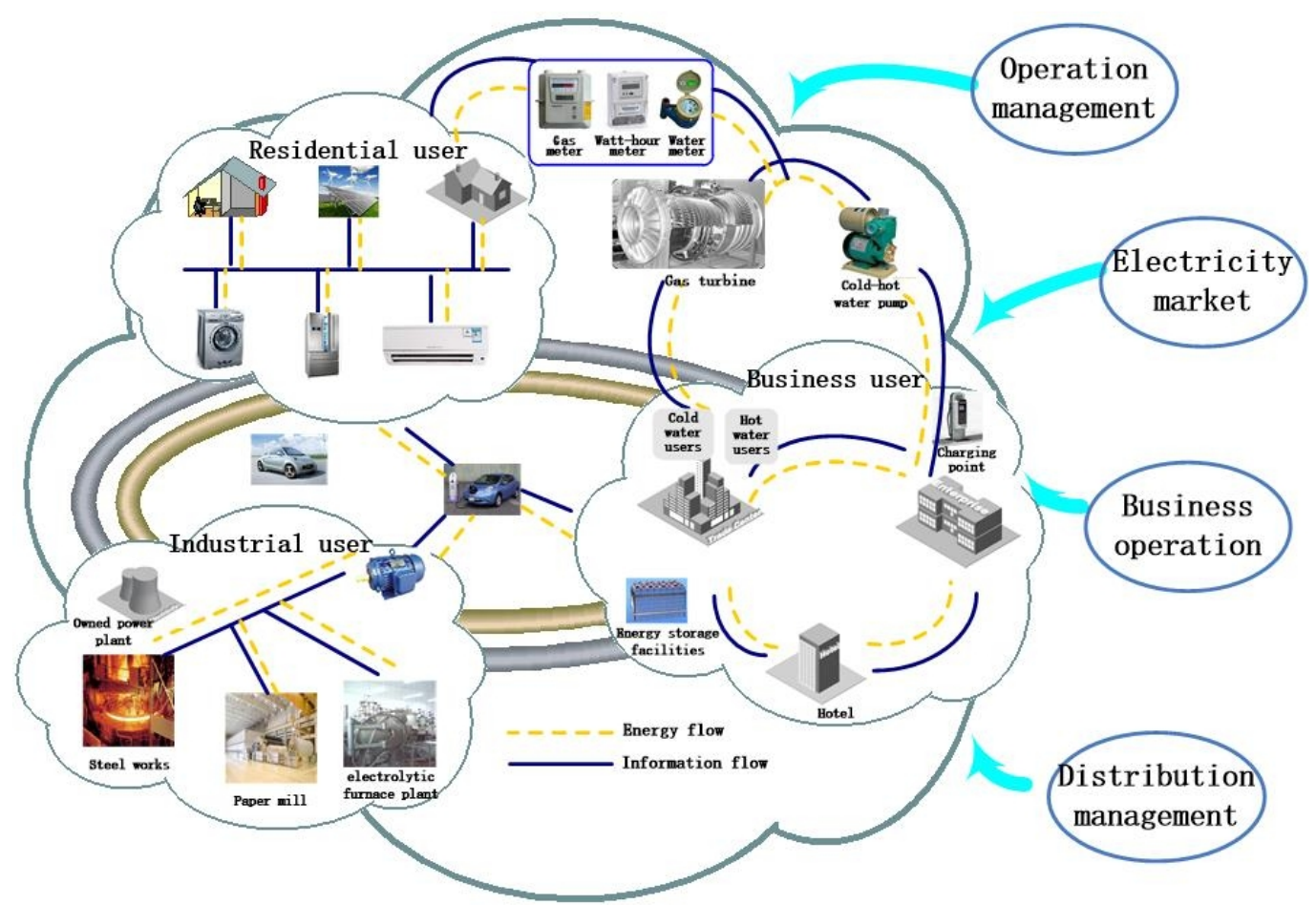

Fig.1 Conceptual model of Interne of energy for user domain

Renewable energy, energy storage and "plug and play" of energy use equipments, that is the harmony of production, supply, use, storage and save energy, realizes connecting and sharing decentralized energy using and distributed energy producing, and realizes the cold thermal power and other energy joint optimized operation. The new characteristics of User Side Internet of Energy are summarized as below: (1) clean: Power generation resources are renewable energy (Geothermal energy, wind energy, solar energy, etc) (2) disperse: A large number of distributed energy system is dispersed in different geographic space, and forms a large-scale energy interconnection network through a large number of scattered nodes. (3) open: User Side Internet of Energy is an equivalent energy sharing network which supports energy bi-directional flow. The user side energy station can plug and play. Each node is equally important and has access to power grid as long as meeting the interoperability standard. (4) interaction: User Side Internet of Energy is able to be coordinate with the smart grid. (5) joint: User Side Internet of Energy can realize primary energy and secondary cooling heating power joint adjustment and control.

\section{Key technology of User Side Internet of Energy}

User Side Internet of Energy is a kind of new type complex energy network, combined with micro electric power grid, heat micro power grid and information network, and particularly shows its comflexity in management and control. Therefore, the following questions of Energy Internet need to be considered on user side:

(1) Pluripotent complementary planning configuration of User Side Internet of Energy

User Side Internet of Energy consists of a large number of pipe network, line and distributed energy system (also known as energy station). Energy station is a system which is located in client or close to the user site, and has independent power supply. This system uses clean energy for power generation, and at the same time make use of waste heat in refrigeration, heating and water heating. Through researching and building comprehensive evaluation index system for power station and designing integration method of production - transportation - transfoming - use - storage of various energy chain integration design method, we can optimize network configuration mode, equipment selection, capacity configuration and operation mode of User Side Internet of Energy. Fully excavate and make use of the complementary and substitution of different energy, we can realize all kinds of energy collaborative optimization from resource to load of the whole link and process. 
(2) District cooling heating power load fine forecasting and joint modeling technology

Based on energy consumption characteristics of industrial and mining enterprises, commercial buildings, residential users, research and design dynamic load forecast method applying to energy planning of User Side Internet of Energy. Reviewing design standards, including main climate zone, typical building type, typical production and living scenes of cool, heat, electricity load can help improve efficiency and accuracy of cold, heat, electricity load forecasting in energy planning and improve the operation efficiency of Energy Internet. Using the modeling tools such as Rational Rose, Enterprise Architect, and building objects and actions model for each object of User Side Internet of Energy can increase the degree of information sharing and provide a good technical support for information interaction of each system and terminal equipment in Energy Internet.

(3) Energy bus system planning and design technology

Energy bus gets A large number of decentralized energy subsystem/equipment togetherl. For example, The renewable heat resource or hot water catchment can be conveyed to the distributed heat pump through pipe network. On the User side, the heat source of the water source heat pump and cooling water chillers are derived from the energy bus system, and return back to source though return line after heat transfer. By studying the energy bus system design principle, system topology structure, advantages, applicability and system form, achieve efficient design of the new type energy bus system. Energy bus system application is shown in Figure 2.

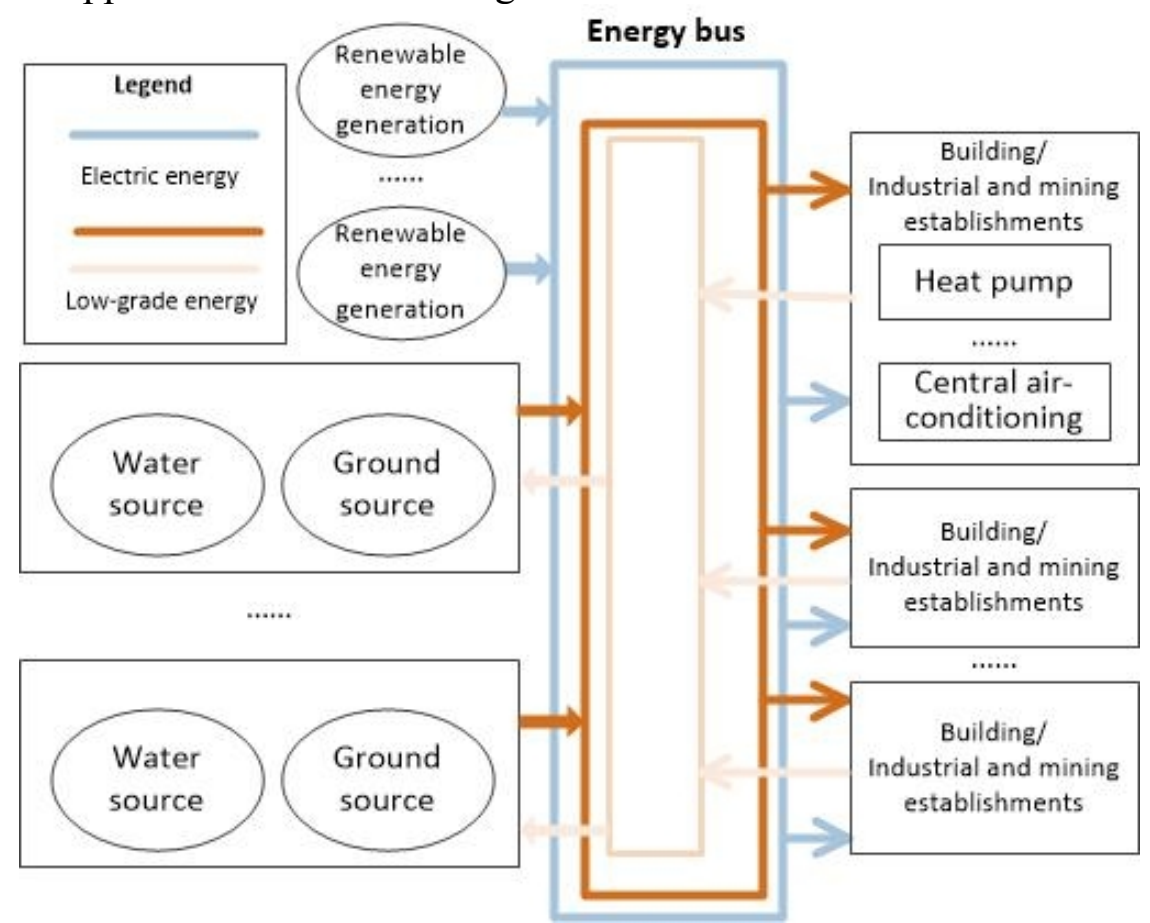

Fig.2 Energy bus system application bus

(4) Operation strategy and control technology of district cooling heating power based on energy

Operation mode of district cooling heating power based on energy bus can provide users with cool, heat and electricity energy, and various forms of energy at the same time, and it is popular with energy echelon use and few pollution. Under the environment of Energy Internet, cooling heating power operation system gives full play to the advantage of using energy echelon use in combined cooling heating and power system; uses renewable energy efficiently; on the basis of the traditional cooling heating power system, integrates distributed renewable power, such as photovoltaic, biomass energy and wind energy, configurates energy storage devices, such as fuel cells, electric power storage and heat storage; effectively improves the energy and environmental benefits by renewable energy power generation and coordinated optimized supply of cooling heating power system. 
(5) The research of the new energy system information modeling technology and control platform The main purpose of the information modeling is finishing the design of the whole system at final through business analysis, demand analysis, use-case mode. Energy Internet shall adopt the CIM (Common Information Model) for moseling, make full use of the relevant classes and property relationship of CIM which are defined, and build generic relationships that could satisfy the requirement of Energy Internet; through capturing by use case model and analysis of the business needs of the users, analyze interaction process of each object and subsystem in business system at different levels; use CIM information model to modeling for energy equipments, systems and control terminals on the user side.

(6) Key technology research of energy local area network autonomous unit interconnection

Energy router is not only the most basic composition of Energy Internet, but also concentrated reflection of information and energy infrastructure integration concept. Energy router can provide interconnection for energy equipment, and provide necessary information communication service for the normal resource allocation and management of Energy Internet. Energy router function structure is shown in Figure 3.

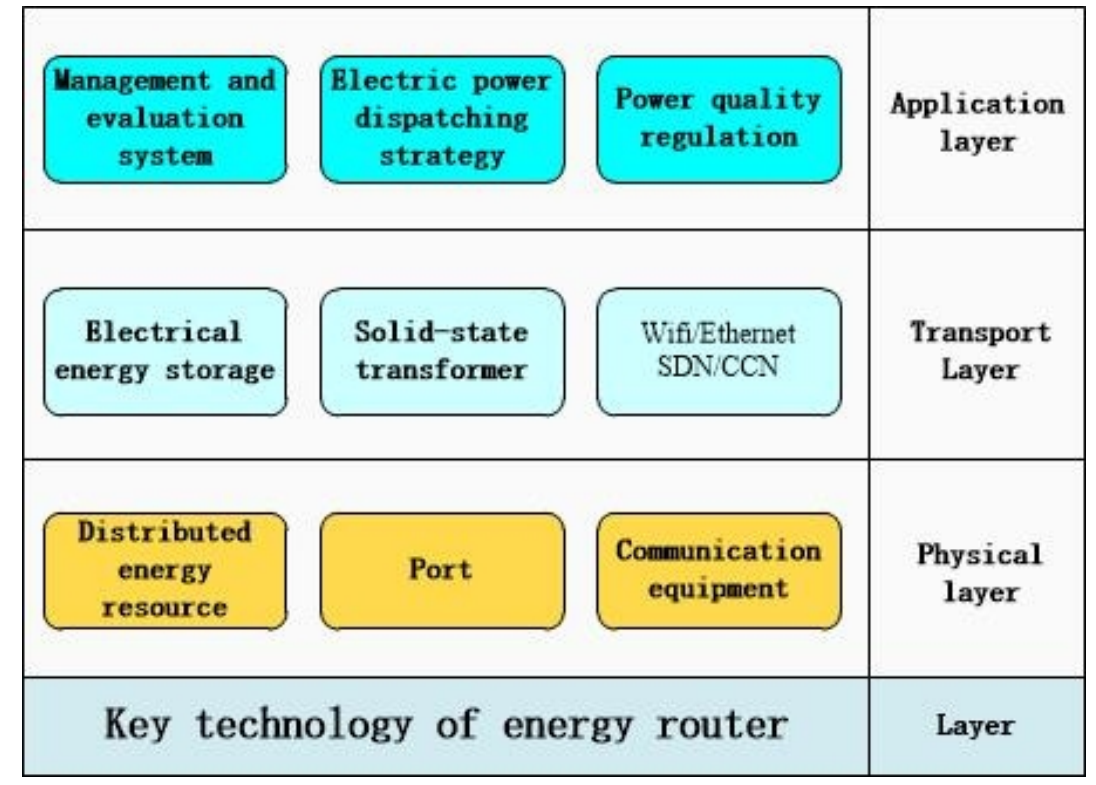

Fig.3 Energy router function structure

In the future energy power internet, energy switch and energy router are basic and indispensable for supporting energy management, and as router plays an important role in the internet. In order to achieve the function of information connection, energy distribution and system status monitoring, energy router architecture consists of three modules: Power electronic device, communication unit and decision making unit [21]. The relationship of general architecture and energy flow is shown in Figure 4. Bold line represents energy flow and dotted line represents information flow. 


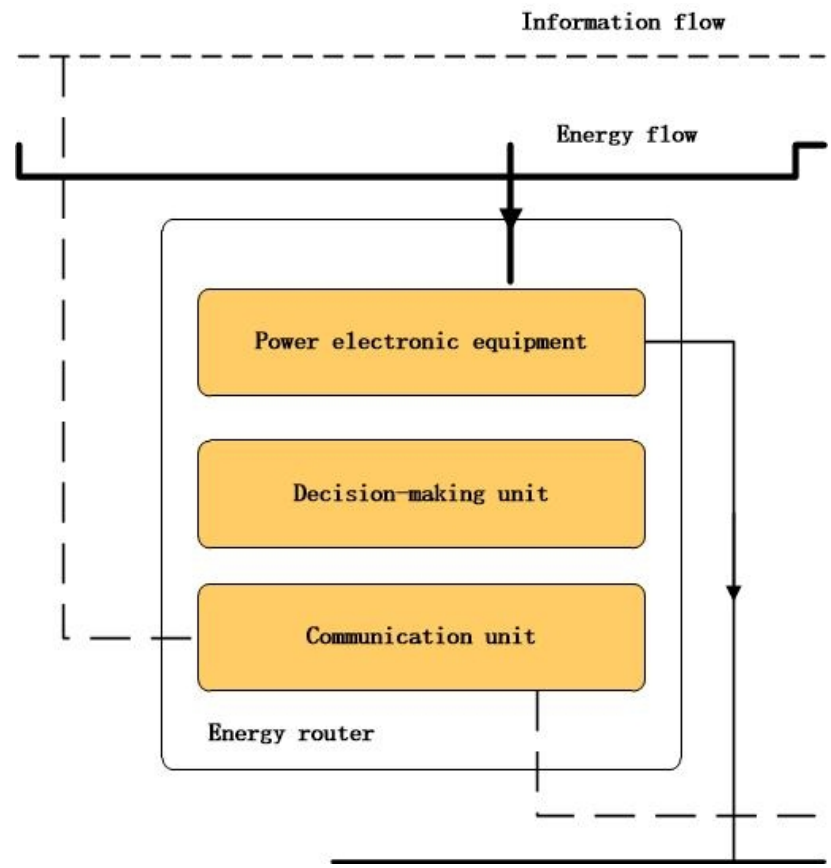

Fig.4 General architecture of energy router

Energy router as a bridge between power resources and users, its main function is the fusion of electric energy from different resources. In addition, in order to realize energy fusion, energy router should guarantee the power quality. At the same time, the energy balance function is required. Taking electric power for example, if the production power is beyond existing local consumer demand, energy router can transmit the rest of electric power to power source near power grid. On the contrary, when local electric power production is insufficient, energy router be used as the local power grid.

(7) The key techniques of user side energy micro network system and smart grid interaction

Energy autonomous unit is considered as "LAN" in Wnergy Internet, such as micro grid and distributed power. Energy Internet will not replace the smart grid In order to meet change and transition of the energy system in Energy Internet, the interaction technology of user side micro energy grid systems and the smart grid is an important part of Energy Internet general architecture. Energy Internet can expand the interconnected scope of power system, and based on the transmission and distribution network, realize the physical connectivity of power systems as well as the information interaction and coordination of huge amounts of distributed devices.

(8) Construction and operation mode research of the new user side energy system

Study comprehensive assessment system and assessment method of district cooling heating power hybrid energy application. Promote supporting policies and incentive mechanism of district cooling heating power hybrid energy large-scale application, district cooling heating power comprehensive energy trading model for multi-scenario, energy saving service mode based on regional integrated energy optimization and utilization, and commercial operation mode of district cooling heating power hybrid energy participating in peak shaving of power grid. Establish sustainable reproducible commercial operation mode of district cooling heating power hybrid energy management service. Implement commercial application of operation mode in concentrated buildings in districts and cities.

\section{The framwork of User Side Internet of Energy}

Different from the traditional operation mode of power grid, energy Internet can dynamically allocate and control the flow of resources and effectively improve the utilization rate of equipment and the operation reliability of power grid by the means of information technology on the basis of the existing grid. By the concept of Internet, energy Internet achieves great changes in energy infrastructure to make the use and sharing of energy as open as Internet. On the user side, two-way interfaces of the smart grid and users are introduced to increase the participation of the user side 
energy equipment and load in traditional grid, to share the peak and valley information of power grid effectively and to optimize the operation of power grid.

As the innovation of energy infrastructure, energy Internet must have the openness and reciprocity which are the characteristics of the Internet, and realize the integration of energy flow and information flow. So, the design and discussion of the framework of energy Internet from the perspective of CPS(Cyber-physical systems) will help to solve and promote the deep integration of energy flow and information flow. Energy Internet can be summarized as the integration of wide area information and energy based on the Internet, which takes the grid as the backbone network and takes the micro network or the distributed energy resources as the local area network. With the establishment of information-centric network model structure and the deep integration of information flow and energy flow, power resources can interact with other resources and even energy consumers, which makes open deployed of energy infrastructure and efficient energy consumption patterns possible. On the basis of the theoretical framework of the energy Internet, information-centric infrastructure frameworks are used for the smart building including commercial buildings and residential areas. All sizes of large power generation equipment connect to the energy Internet through energy backbone, and residential areas, industrial parks, all kinds of energy-using equipment obtain the required energy supply from the local distributed user side energy network, as shown in Figure 5.

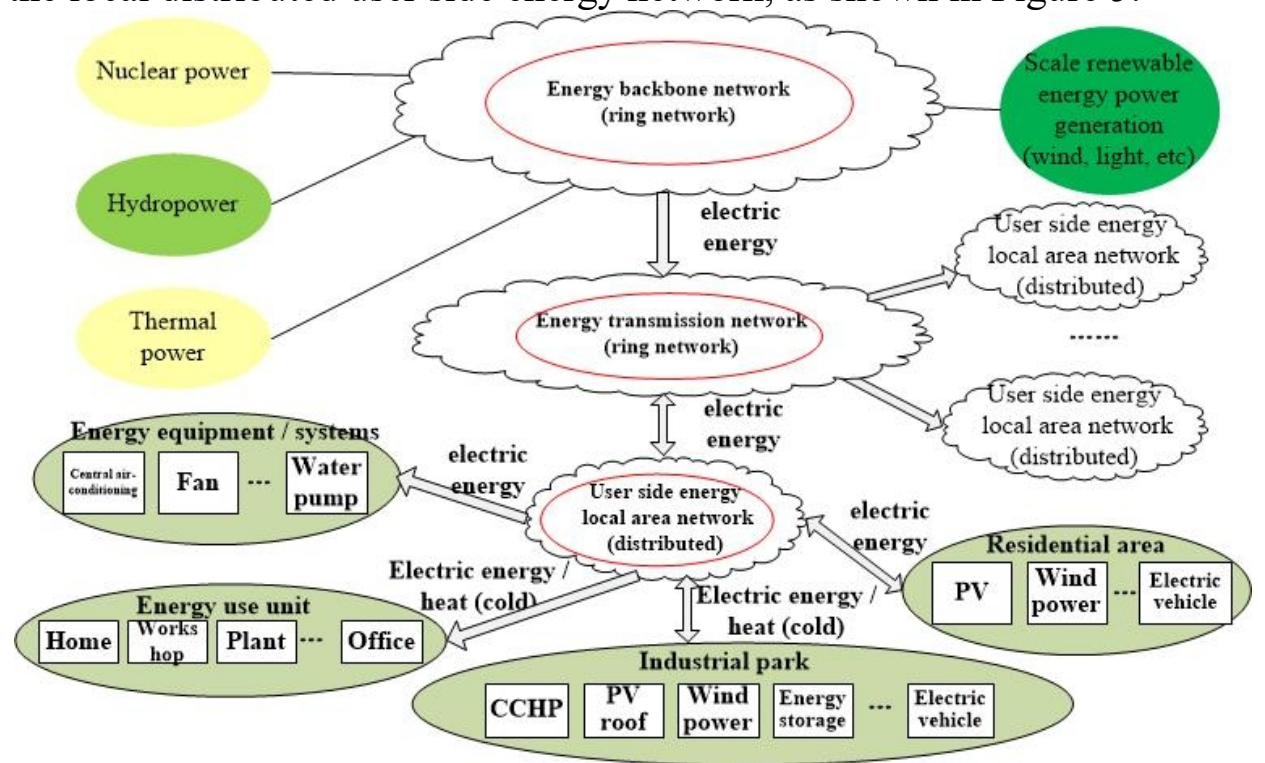

Fig.5 Energy Internet basic infrastructure

The framework provides a distributed integrated energy management system, which can achieve infrastructure configuration in the process of buffering energy and delaying the intergation of information infrastructure.

Aiming at the energy Internet user side information interaction, three most important basic services were discussed, and established the supporting mechanism for the service function and mutual interaction process, as shown in Figure 6. 


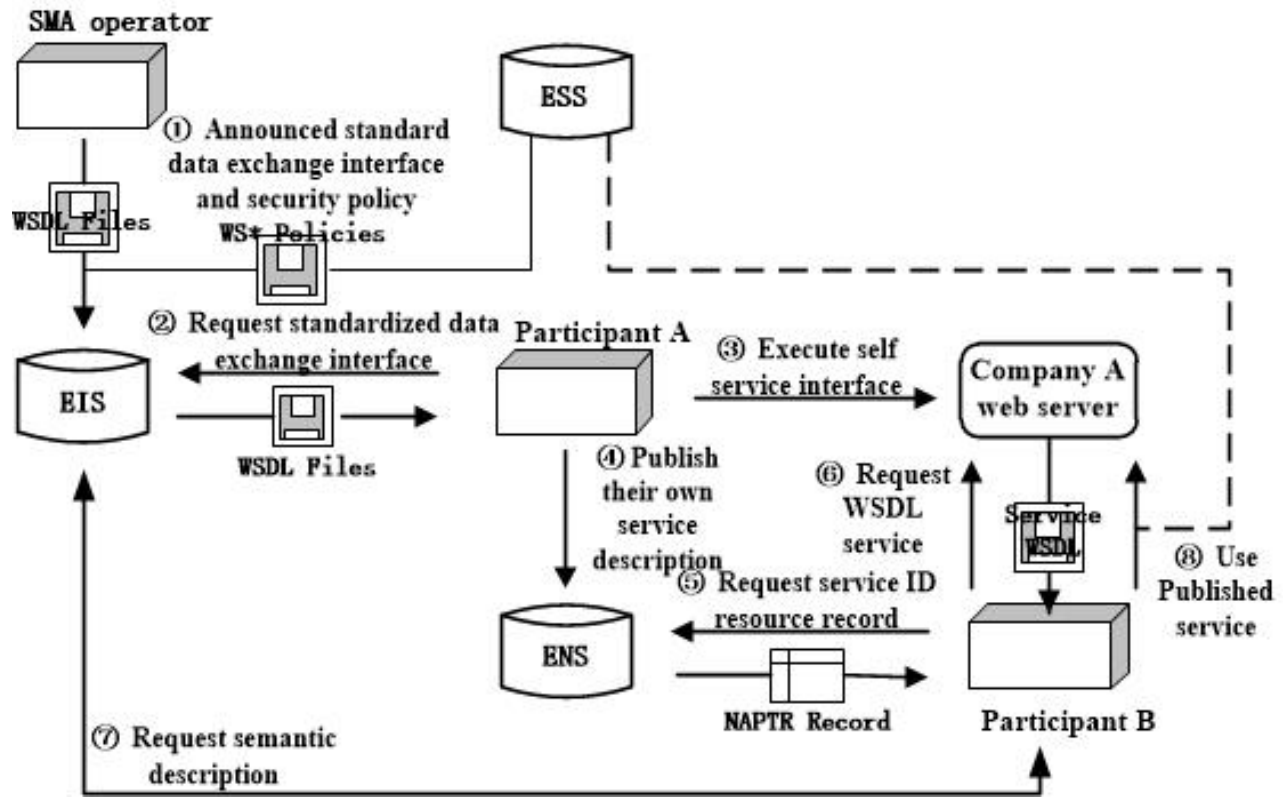

Fig.6 Informational support schema of the user side Internet of energy

The three services are the electric interface service, the electric name service and the electric security service, and the service functions are as follows:

(1) EIS (electric interface service): provide standardized business process, interface, data format and security policy for the implementation of web services.

(2) ENS (electric name service): identify all elements of the energy Internet (such as the operators of distribution network, suppliers, customers, measuring points, etc.) and provide additional information about the search elements.

(3) ESS (electric security service): define security policies and additional protection measures for secure communication.

The above three kinds of service support market participants to participate in the whole process of the implementation of the system from the stage of service design (design time) to the actual business implementation (run time). The Interactive steps in Fig.6 and intelligent architecture have similarity in the ebXML mechanism.

Participant A:The operators of smart buildings publish standardised process, data exchange format, machine readable interface and security policy (step 1). A is able to request information about data exchange interface from the EIS (step 2) and achieve its own Web services in the form of WSDL(Web service description language) which is machine-readable (step 3). "A" can publish and manage information through the ENS in the location of the Web service (step 4), and store it in the NAPTR (Naming Authority Pointer).

Participant B: another participant B have business contacts with A, resolve the ID of participant A in ENS and request each service location (step 5). B can request custom service WSDL files (step 6) from the location of the known Web server and get the semantic information of all service details from EIS (step 7).

In the future operation system of energy Internet, the participants A correspond to the aggregators, while the participant B corresponds to the power users. 


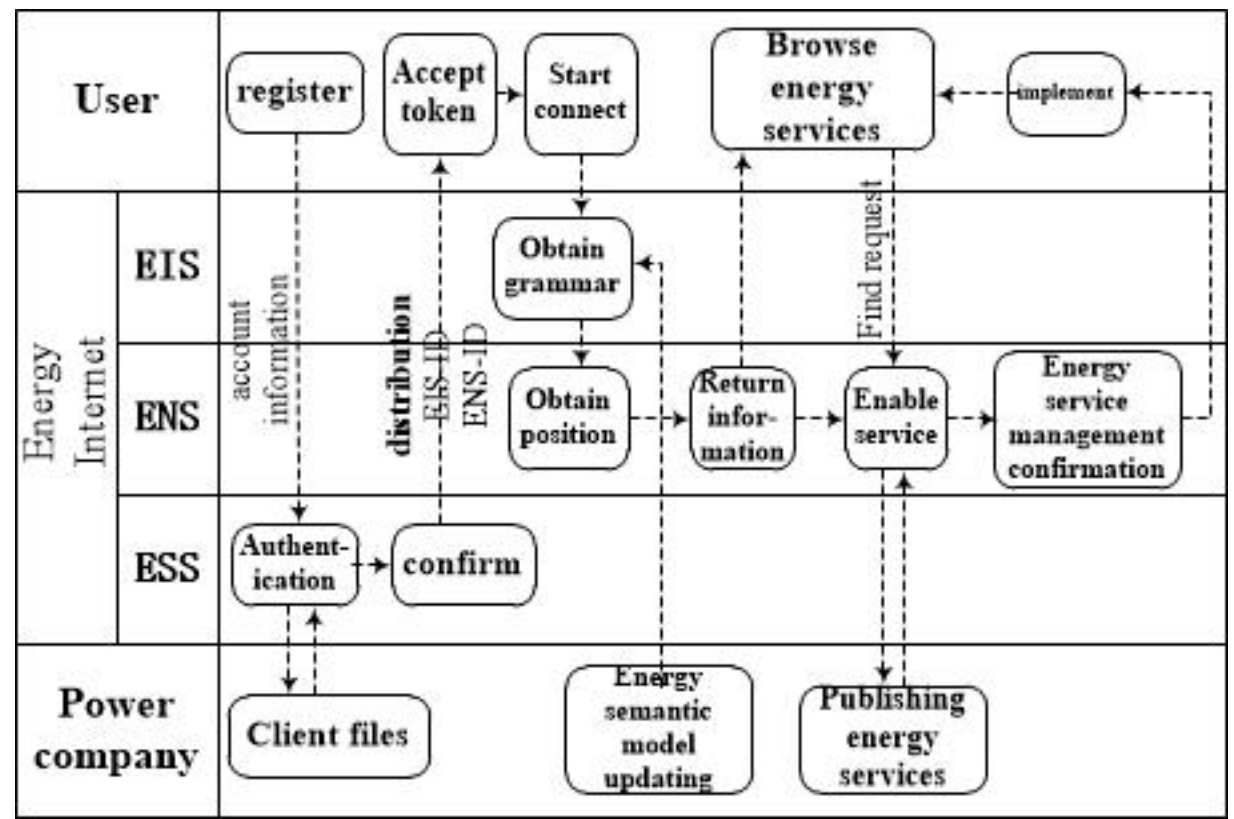

Fig.7 Interactions between essential entities of IoE

Figure 7 shows the logic of information interaction among various functional entities in the energy Internet. The grid corporation issued standard data exchange format and security policy through local energy data exchange interface, and aggregators can resolve the interface service released by the grid corporation and provide specific energy services in the local implementation by WSDL files. In order to support the energy services for users under the jurisdiction of the aggregators, aggregators can selectively achieve the functions specified in the WSDL files, and publish additional retrieval information via ENS. Users can choose the type of service from ENS according to the needs. In the transfer process of energy information, ESS is responsible for the entire supervision. The users who register for the first time need to get energy services interface syntax interpretation through EIS first to interact with ENS. The electric power companies are mainly responsible for the management of customer files, the update of energy semantic model and the release of energy services, and they have connection with EIS 、 ENS 、 ESS. Different from the previous power industry standards, the interconnection between different roles of energy Internet do not adopt the bit oriented communication mode, but the advanced object-oriented thought, which only needs to describe the information model. When the service of the system is updated, only the semantics of the models and rules of grammar but not all systems need to be updated.

\section{Conclusions}

By information technology and power electronic technology, Energy Internet makes a large number of distributed power and energy storage devices interconnected to form a true sense of the smart green grid. However, considering that the renewable energy is uncertain and uncontrolled and electricity pricing policy in the future is fuzzy, the load on the user side still presents uncertainty. In the future development of energy Internet, real time price, automatic demand response and other incentive mechanism are all supposed to be taken into account. Master the law of load change by analysing user behavior to reduce the uncertainty of system, optimize the power grid dispatch and operation. This paper analyzed the key technologies of the energy Internet, initially established the energy Internet information frame to attract the attention of the academic circles to the energy Internet, and promote the development of energy Internet together.

\section{Acknowledgements}

This work was financially supported by the SGCC's Science Technology Project, Research of Automation Demand Response Simulation Technology Adapted to the Retail Side Opening-up. 


\section{References}

[1] DONG Zhaoyang,ZHAO Junhua,WEN Fushuan,XUE Yusheng. From Smart Grid to Energy Internet: Basic Concept and Research Framework[J]. Automation of Electric Power Systems. 2014,38(15):1-11.

[2] RIFKIN J. The third industrial revolution: how lateral power is transforming energy, the economy, and the word[M]. New York: Palgrave MacMillan, 2011.

[3] U.S. Department of Energy, "Smart Grid System Report”, 2009

[4] .LIU Zhenya. Smart grid and the third industrial revolution[J]. Guangxi Electric Power, 2013, $164,84-87$.

[5] .LIU Zhenya. Global energy Internet[M]. China Electric Power Press,2015

[6] HUANG A Q. FREEDM System-A Vision for the Future Grid[C]// IEEE Power and Energy Society General Meeting, 2010:1-4.

[7] HUANGAQ, CROWM L, HEYDT G T, et al. The Future Renewable Electric Energy Delivery and Management ( FREEDM ) System: The Energy Internet[J]. Proc the IEEE, 2011, 12(17) : $133-148$.

[8] .LUO Huihong,ZHANG Guoyi,CAI Yaoguang,ZHUO Yue. Design of Smart Grid Architecture Model Based on Information Flow[J]. Information \& Communications,,2013,10:71-72

[9] .FANG Chen,LING Ping,BAO Hailong,ZHANG Yu.Smart Grid Architecture with a High Proportion of Renewable Energy Utilization[J]. East China Electric Power. 2013, 12: 2468-2471.

[10].GONG Gangjun,SUN Yi,CAI Mingming,WU Runze,TANG Liangrui.Research of network architecture and implementing scheme for the internet of things towards the smart grid[J]. Power System Protection and Control, 2011,20:52-58.

[11] Junwei Cao; Mingbo Yang, "Energy Internet -- Towards Smart Grid 2.0," Networking and Distributed Computing (ICNDC), 2013 Fourth International Conference on , vol., no., pp.105,110, 21-24 Dec. 2013

[12] Scheibmayer, M.; Deindl, M., "An ICT architecture to support business processes in the Internet of Energy," eChallenges, 2010 , vol., no., pp.1,8, 27-29 Oct. 2010

[13]L. H. Tsoukalas, R. Gao. From Smart Grids to an Energy Internet -- Assumptions, Architectures and Requirements. [C]//Third International Conference on Electric Utility Deregulation and Restructuring and Power Technologies, 94-98, April 2008.

[14] L. H. Tsoukalas, R. Gao. Inventing energy internet: The role of anticipation in human-centered energy distribution and utilization[C]/Proc of IEEE SICE08. Piscataway, NJ: IEEE, 2008:399-403.

[15]CAO Junwei,YANG Mingbo,ZHANG Dehua,et al.Energy Internet: an Infrastructure for Cyber-Energy Integration[J]. Southern Power System Technology. 2014, 8(4): 1-10

[16] SHEN Zhou,ZHOU Jianhua,YUAN Xiaodong,YANG Wei.Development and Suggestion of the Energy-Internet[J]. Jiangsu Electrical Engineering.2014,33(1):81-84.

[17] HAN Dongduo, YU Yixin, et al. The future of smart grid is the energy of the Internet[J]. China Strategic Emerging Industry,2014,22:44-45

[18] CI Song,LI Hongjia,CHEN Xin,et al.The cornerstone of energy internet: research and practice of distributed energy storage technology[J]. Scientia Sinica(Informationis), 2014, 44(6) : 762-773.

[19] WANG Jiye,MENG Kun,CAO Junwei,et al.Information Technology for Energy Internet: A Survey[J], Journal of Computer Research and Development. 2015,52(3):1-18. 
[20]ZHA Yabing,ZHANG Tao,HUANG Zhuo,et al.Analysis of energy internet key technologies[J]. Scientia Sinica(Informationis), 2014,44(6):702-713.

[21] Yi Xu; Jianhua Zhang; Wenye Wang, et al. "Energy router: Architectures and functionalities toward Energy Internet," Smart Grid Communications (SmartGridComm), 2011 IEEE International Conference on , vol., no., pp.31,36, 17-20 Oct. 2011

[22]ZHAO Junhua,WEN Fushuan XUE Yusheng,et al.Cyber Physical Power Systems: Architecture, Implementation Technology and Challenges[J]. Automation of Electric Power Systems. 2010,34(16):1-7 